\title{
승용차용 $\mathrm{LED}$ 전조등 방열 성능 최적화에 관한 연구 \\ 박상준 ${ }^{1}$, 이영림 ${ }^{*}$ \\ ${ }^{1}$ 공주대학교 기계자동차 공학부
}

\section{A Study on Optimization of Thermal Performance of a LED Head Light for Passenger Cars}

\author{
Sang Jun Park ${ }^{1}$ and Yoing Lim Lee ${ }^{1^{*}}$ \\ ${ }^{1}$ Dept. of Mecharnical and Automotive Engineering, Kongju National University
}

요 약 LED(Light Emitting Diode) 조명기기는 장수명, 저탄소, 고효율의 장점을 가지고 있어 현재 가정용 램프, 자 동차 조명등, 신호등에 널리 사용되고 있다. 본 연구에서는 자동차 LED 전조등용 MCPCB LED를 제작한 후 방열성 능 최적화를 수행하였다. 개발된 LED 전조등은 히트파이프와 팬의 조합시 목표 방열성능 달성이 가능하였고 팬의 on-off 제어를 통해 팬의 수명 또한 3 배 정도 연장 가능함을 보였다.

\begin{abstract}
Since LED lights have advantages of long life, low-carbon and high efficiency, they have been widely used as household lamps, automotive lighting, traffic lights etc. In this study, MCPCB LED lamps for automotive LED headlights were manufactured and the performance of heat release was optimized. The developed LED headlight satisfied the target thermal performance with heat pipes and fans, and it was also shown that fan life can be prolonged three times by fan on-off control.
\end{abstract}

Key Words : LED, Head light, Heat sink, Heat pipe, Optimization, Fan

\section{1. 서론}

자동차 전조등은 그 동안 할로겐 램프가 많이 사용되 어 왔으며 그림 1 에 전형적인 $55 \mathrm{~W}$ 급 할로겐 전조등 램 프를 나타냈다. 하지만, 최근 들어 자동차 조명 시스템에 우수한 내구성 및 빠른 응답성, 반영구적인 수명, 낮은 소 비전력을 가지고 있는 LED 램프의 적용 비중이 높아지 고 있다. 특히 고출력 전조등용 LED 램프가 개발되면서 세계의 자동차 램프 업계는 저탄소, 친환경 자동차의 전 조등에 이러한 LED 램프를 적용하고 있다.

할로겐 램프 $50 \mathrm{~W}$ 의 경우 유사한 밝기를 내기 위해서 는 $\mathrm{LED}$ 램프는 약 $8 \sim 10 \mathrm{~W}$ 의 용량이 필요하다. 이는 LED 램프가 할로겐 램프에 비해 약 $80 \%$ 효율이 더 우수 하기 때문이며 수명 또한 할로겐 램프에 비해 10 배 이상 길다. 표 1 에 $\mathrm{LED}$ 램프와 할로겐 램프의 성능을 비교하 였다[1].

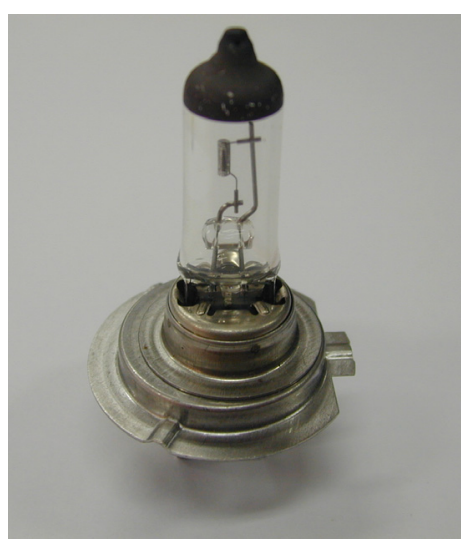

[그림 1] 자동차 전조등용 $55 \mathrm{~W}$ 급 할로겐 램프

[Fig. 1] $55 \mathrm{~W}$ halogen lamp for a head lamp of passenger cars

"교신저자 : 이영림(ylee@kongju.ac.kr)

접수일 11년 09 월 14 일 수정일 (1차 11년 12월 02일, 2차 11년 12월 22일, 3 차 12 년 01 월 03 일) 게재확정일 12 년 01 월 05 일 
[표 1] LED와 할로겐 램프 성능 비교

[Table 1] Comparison of performances of LED and halogen lamps

\begin{tabular}{|c|c|c|}
\hline & LED & Halogen \\
\hline 광효율 $(\mathrm{lm} / \mathrm{W})$ & 100 & 30 \\
\hline 소비전력 $(\mathrm{W})$ & 10.5 & 57 \\
\hline $\begin{array}{c}\text { 등 수명(hour) } \\
\text { (6시간/일 기준) }\end{array}$ & 50,000 & 3,000 \\
\hline
\end{tabular}

한편, LED 램프는 칩(chip) 접합부의 온도가 $135 \sim 150$ ${ }^{\circ} \mathrm{C}$ 가 되면 칩 단선 현상이 발생하여 그 기능을 상실하게 된다. 따라서, LED 칩 접합부의 단선을 예방하고 LED 램프의 효율 및 수명 연장을 위해서는 효율적인 냉각이 요구된다.

최근 들어 LED 조명의 방열성능 향상을 통한 효율 및 내구성 향상에 관한 연구가 많이 이루어지고 있다. 그 중 $\mathrm{Kim}$ 등[2]은 다수의 저출력 칩을 이용하여 히트파이프 유무에 따른 정션온도를 비교하였다. Liu 등[3]은 마이크 로 제트(micro jet)를 이용한 강제 냉각 기술을 연구하였 고 마이크로 제트를 이용하여 LED 기판온도를 추가적으 로 $23{ }^{\circ} \mathrm{C}$ 감소시킬 수 있음을 보였다. Chen 등[4]은 LED 칩과 $\mathrm{MCPCB}$ (metal core printed circuit board)의 결합시 접촉저항이 방열 성능에 미치는 영향을 수치해석과 실험 을 통하여 비교하였다. 이러한 $\mathrm{MCPCB}$ 는 기존 에폭시 레 진 기판보다 금속을 사용하므로 열전도성이 우수하다.

Kang 등[5]은 차량용 LED의 히트싱크의 방열 면적과 핀(fin)의 길이 변화에 대한 상관관계를 도출하여 히트 싱 크에 의한 LED 방열 시스템이 2 차 열원의 영향을 비교 하였다. Weng[6]은 LED 조명기기 제품 개발을 위한 열 설계법칙과 상호작용을 파악하기 위해 수치해석을 통한 $0.1 \sim 1 \mathrm{~W}$ 의 출력에 따른 $\mathrm{PCB}$ 물성, 냉각조건, 칩 크기 등 의 다양한 조건에서 저항과 정션온도 관계를 연구하였다. Hwang[7, 8]등은 $10 \mathrm{~W}$ LED 조명등의 히트싱크 형상 변 경, $\mathrm{PCB}$ 물성 변경 및 저출력 $\mathrm{LED}$ 를 사용하였을 때 정 션온도를 예측하였고, 팬의 on-off 제어를 통해 팬의 수명 이 연장될 수 있음을 보였다.

본 논문에서는 자동차 전조등용 $18 \mathrm{~W}$ 및 $24 \mathrm{~W}$ 급 $\mathrm{MCPCB}$ LED 시제품을 제작하고 방열 성능을 확보하고 자 한다. 이를 위해 히트싱크, 히트파이프 및 팬 등을 고 려하고 이들의 최적화를 수행한다. 또한 팬의 on-off 제어 를 통한 팬 수명 연장방법도 제시한다.

\section{2. 실험 준비 및 방법}

$\mathrm{LED}$ 방열 실험은 $18 \mathrm{~W}$ 및 $24 \mathrm{~W}$ 의 출력을 가진 $\mathrm{LED}$
를 대상으로 수행하였다. LED 칩온도는 측정이 어려우 므로 그림 2 와 같이 $\mathrm{LED} \mathrm{PCB}$ 의 전극에 T형 열전대를 부 착하여 $\mathrm{PCB}$ 의 온도를 측정하였다.

방열성능을 알아보기 위하여 히트싱크, 히트 파이프, 그리고 팬을 이용하여 표 2에서와 같이 5 가지 경우를 고 려하였다. 실험은 $\mathrm{LED}$ 에 전력을 인가한 후 열평형 상태 가 될 때까지 수행하였다. 그림 3은 LED를 히트싱크에 부착시킨 모습을 보여준다. 또한, 그림 4는 LED에 히트 파이프와 팬을 장착한 경우를 나타낸다. 사용한 히트싱크 와 히트파이프 그리고 팬의 사양은 표 3 에 나타내었다.

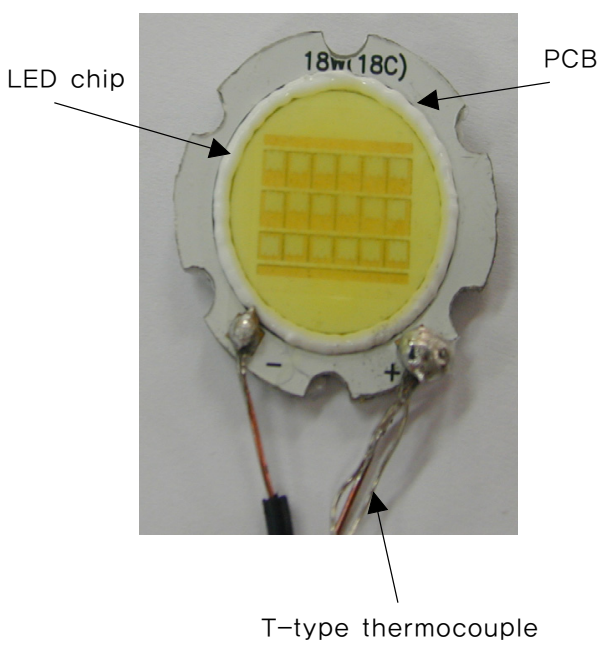

[그림 2] $18 \mathrm{~W}$ LED 와 T-타입 열전대

[Fig. 2] $18 \mathrm{~W}$ LED and T-type thermocouple

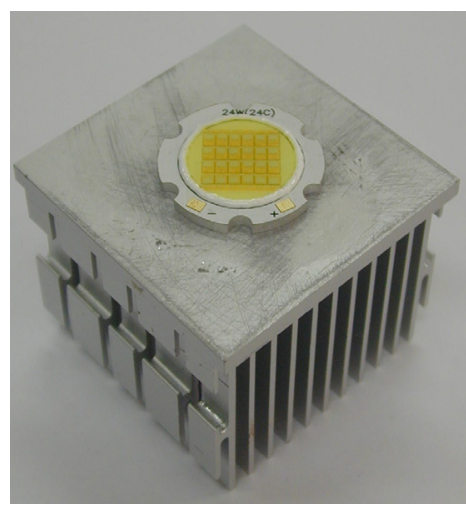

[그림 3] 히트싱크와 LED

[Fig. 3] Heatsink and LED 


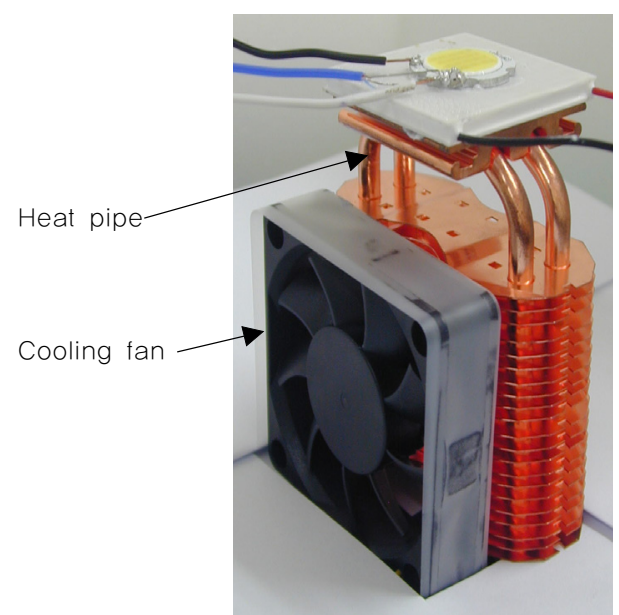

[그림 4] 히트 파이프와 팬을 이용한 방열성능 실험

[Fig. 4] Experiment for thermal performance with the heatpipe and the fan

[표 2] 방열 성능 최적화를 위한 냉각 실험

[Table 2] Cooling experiment for optimization of thermal performance

\begin{tabular}{l||l}
\hline & Cooling method \\
\hline \hline Case 1 & None \\
\hline Case 2 & Heat sink \\
\hline Case 3 & Heat sink + Fan \\
\hline Case 4 & Heat pipe with fins \\
\hline Case 5 & Heat pipe with fins + Fan \\
\hline
\end{tabular}

[표 3] 방열기구 성능 사양

[Table 3] Specifications of heat release equipment

\begin{tabular}{c||c|c|c}
\hline & Heat sink & Heat pipe & Fan \\
\hline \hline $\mathrm{W} \times \mathrm{H} \times \mathrm{L}(\mathrm{mm})$ & $38 \times 37 \times 27$ & - & - \\
\hline Diameter(mm & - & 5 & - \\
\hline Number of fin & 11 & 21 & - \\
\hline Fin pitch(mm) & 2.6 & 2.6 & - \\
\hline Manufacturer & China & China & $\begin{array}{c}\text { AGE06015 } \\
\text { B12H, } \\
\text { China }\end{array}$ \\
\hline RPM & - & - & 4800 \\
\hline
\end{tabular}

\section{3. 결과 및 토론}

\section{1 자동차 전조등 LED 램프 시제품 제작}

자동차에서 사용할 수 있는 LED 램프를 개발하기 위
하여 고출력 단일 LED칩 대신 복수 개의 저출력 $\mathrm{LED}$ 를 선택하였다. 이는 단일 고출력 LED 칩에 비해 저출력 LED 칩을 여러 개 사용하면 열밀도를 분산시킬 수 있기 때문이다. $1 \mathrm{~W}$ 의 LED 칩 6개를 직렬로 연결하여 한 줄 로 만든 후, $18 \mathrm{~W}$ 는 3 줄, $24 \mathrm{~W}$ 는 4줄로 구성하였는데 각 줄끼리는 병렬로 연결하였다. 기판은 $\mathrm{MCPCB}$ 타입으로 선정하였고 그림 5 에 $18 \mathrm{~W}$ 및 $24 \mathrm{~W}$ 의 $\mathrm{LED}$ 램프를 각각 나타냈다.

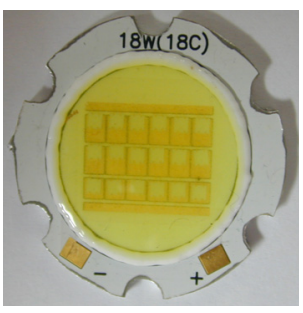

(a) $18 \mathrm{~W}$ LED

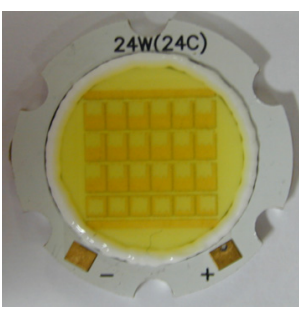

(b) $24 \mathrm{~W}$ LED
[그림 5] $18 \mathrm{~W}$ 와 $24 \mathrm{~W}$ LED 램프

[Fig. 5] $18 \mathrm{~W}$ and $24 \mathrm{~W}$ LED lamps

\subsection{LED 방열 성능 실험}

먼저 LED에 어떠한 방열장치도 장착하지 않은 상태 에서 전압을 인가하였다. 이 때 시간에 따른 $\mathrm{MCPCB}$ 의 온도변화를 그림 6 에 나타냈다.

$18 \mathrm{~W}$ 의 경우 24 초 경과시 이미 $108{ }^{\circ} \mathrm{C}$ 를 상회하였고 $24 \mathrm{~W}$ 의 경우는 24 초에서 $118{ }^{\circ} \mathrm{C}$ 의 온도를 기록하였다. $\mathrm{LED}$ 의 온도가 과도하게 상승하면 칩의 단선이나 수명 단축을 초래하므로 더 이상의 실험은 수행하지 않았다.

그림 7은 $\mathrm{MCPCB}$ 에 전열면적 $0.2 \mathrm{~m}^{2}$ 인 히트싱크를 부 착하였을 때 시간에 따른 $\mathrm{MCPCB}$ 온도변화를 보여준다. 어떠한 방열장치를 사용하지 않았을 경우보다는 냉각성 능이 개선되었지만 여전히 $18 \mathrm{~W}$ 는 300 초, $24 \mathrm{~W}$ 의 경우 180 초 경과 후 $100{ }^{\circ} \mathrm{C}$ 를 초과하게 된다. 이는 히트싱크의 자연대류만으로는 냉각이 불충분하여 좀더 효과적인 방 열장치가 필요하다는 것을 의미한다. 좀 더 효율적인 냉 각성능을 위하여 히트싱크에 팬을 부착하여 강제대류를 발생시켰는데, 그림 8 에 시간에 따른 $\mathrm{MCPCB}$ 온도변화 를 나타냈다.

열평형이 이루어진 후 $\mathrm{PCB}$ 최고온도는 $18 \mathrm{~W}$ 가 약 60 ${ }^{\circ} \mathrm{C}, 24 \mathrm{~W}$ 는 약 $67{ }^{\circ} \mathrm{C}$ 로 나타났다. 이는 강제대류를 이용 할 경우 $24 \mathrm{~W}$ 의 고출력에서도 $70{ }^{\circ} \mathrm{C}$ 이하로 나타나 LED 의 내구성 확보가 가능함을 보였다. LED 칩온도는 일반 적으로 $150{ }^{\circ} \mathrm{C}$ 이상 증가하게 되면 $\mathrm{LED}$ 의 수명 및 효율 이 급격히 저하하여 내구성에 문제가 발생한다. 


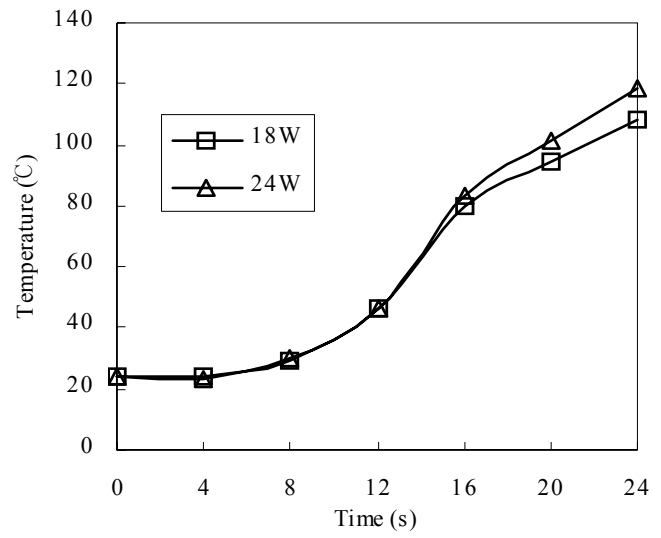

[그림 6] 시간에 따른 단일 LED 온도변화

[Fig. 6] Variations of a LED temperature with time

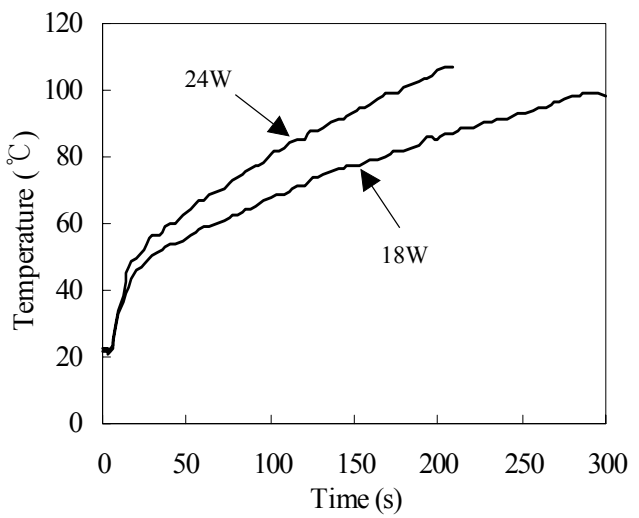

[그림 7] 히트싱크를 이용한 시간에 따른 LED 온도 변화

[Fig. 7] Variations of temperature for heatsink with time

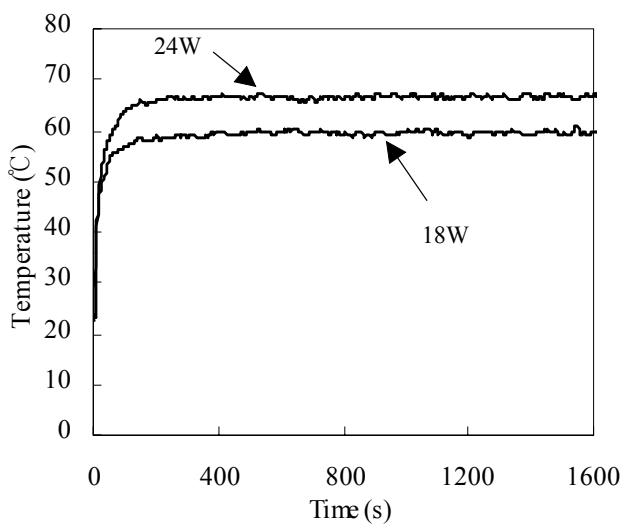

[그림 8] 히트싱크와 팬을 이용한 경우 시간에 따른 LED 온도변화

[Fig. 8] Variations of LED temperature with time for heatsink and fan
그림 9에 핀이 부착된 히트파이프 사용 시 자연대류 상태에서 시간에 따른 $\mathrm{MCPCB}$ 온도변화를 나타냈다. 히 트싱크만 사용하였을 경우에 비해 급격한 온도상승은 나 타나지 않았지만 $18 \mathrm{~W}$ 의 경우 1160 초, $24 \mathrm{~W}$ 의 경우는 390 초 경과후에 $\mathrm{MCPCB}$ 의 온도가 $100{ }^{\circ} \mathrm{C}$ 에 도달하였 다. 이것은 결국 히트파이프를 사용하더라도 자연대류로 부터 얻을 수 있는 열전달계수가 너무 작아 방열이 불충 분함을 알 수 있다.

그림 10 은 히트파이프와 팬을 이용하였을 때 시간에 따른 $\mathrm{MCPCB}$ 의 온도변화를 나타낸다. $\mathrm{MCPCB}$ 온도는 $18 \mathrm{~W}$ 에서 약 $42{ }^{\circ} \mathrm{C}, 24 \mathrm{~W}$ 에서는 약 $53{ }^{\circ} \mathrm{C}$ 로 나타나 히 트싱크와 팬을 조합한 경우보다 더욱 효과적임을 알 수 있다.

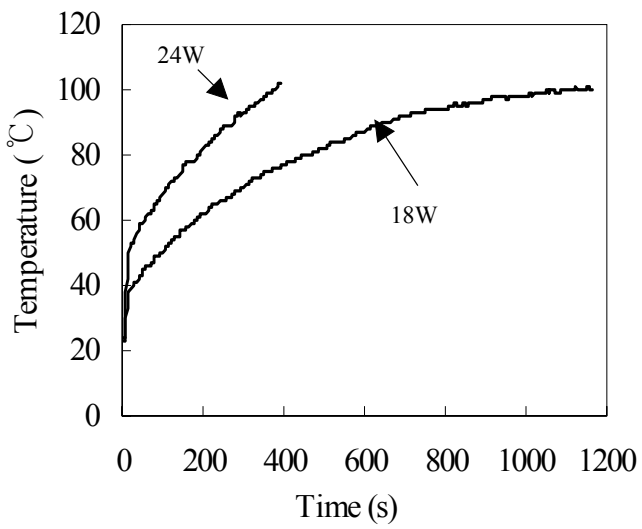

[그림 9] 히트파이프를 이용한 경우 시간에 따른 LED 온 도변화

[Fig. 9] Variations of LED temperature with time for heat pipe

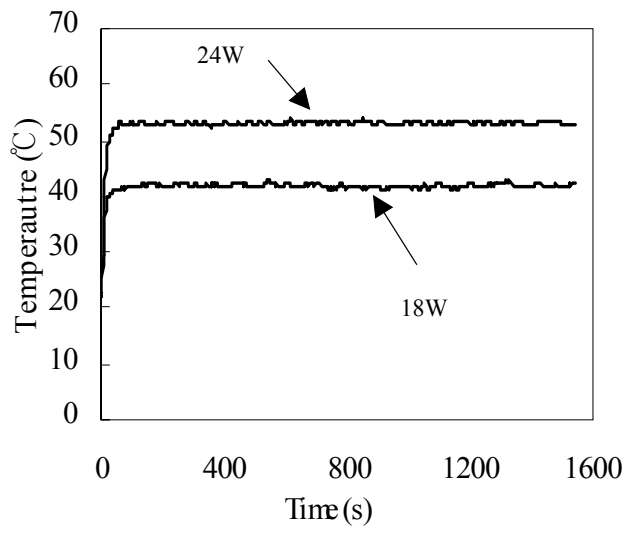

[그림 10] 히트파이프와 팬을 이용한 경우 시간에 따른 LED 온도변화

[Fig. 10] Variations of LED temperature with time for heat pipe and fan 


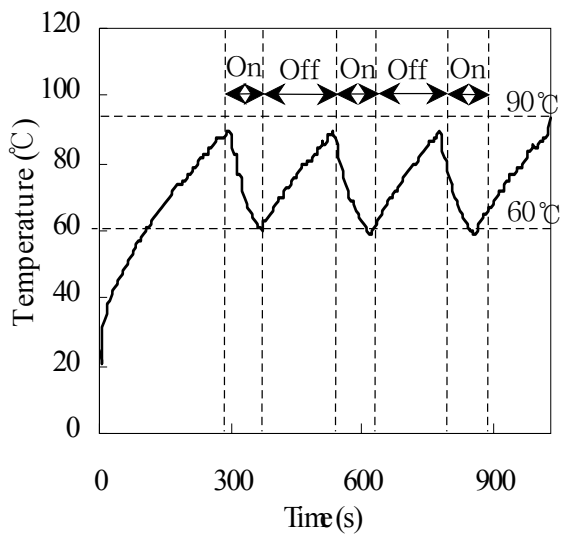

[그림 11] 팬 작동 제어에 따른 온도 변화

[Fig. 11] Variations of temperature with time for fan on-off control

\section{3 팬 작동 제어}

보통 팬의 수명은 $\mathrm{LED}$ 의 수명보다 작고 또 팬 작동시 소음이나 추가 전력소모를 야기한다. 따라서, 팬의 기동정지 제어를 이용하면 팬의 수명을 연장할 수 있다. 본 연구에서는 $\mathrm{PCB}$ 의 목표온도를 $60{ }^{\circ} \mathrm{C} \sim 90{ }^{\circ} \mathrm{C}$ 로 설정하 고 팬을 제어하였다. 그림 11 에 팬의 제어에 따른 $18 \mathrm{~W}$ $\mathrm{LED}$ 램프의 $\mathrm{MCPCB}$ 온도변화를 시간의 변화에 따라 나 타냈다. $90{ }^{\circ} \mathrm{C}$ 에서 $60{ }^{\circ} \mathrm{C}$ 까지 하강시키는데 필요한 팬 작 동시간은 평균 104 초로 판명되었고, $55{ }^{\circ} \mathrm{C}$ 에서 $90{ }^{\circ} \mathrm{C}$ 까 지 승온하는데 걸리는 시간은 약 180 초이다. 따라서, 팬 기동시 기동전력이나 베어링 마모를 고려하지 않는다면 팬의 작동 제어를 통하여 팬의 수명 및 팬의 전력소비를 약 2.7 배정도 향상시킬 수 있을 것으로 기대된다.

\section{4. 결론}

본 연구는 자동차 LED 전조등의 방열 성능 최적화를 위해 히트싱크, 히트파이프, 팬 등의 효율성을 살펴보았 고, 팬의 작동-정지를 통한 방열성능을 고찰하였다. 이러 한 연구를 통해 얻은 결론은 다음과 같다.

(1) 자동차 헤드라이트의 경우 협소한 공간으로 인하 여 고출력 $\mathrm{LED}$ 의 소형화에 따른 $\mathrm{LED}$ 칩의 열분 산이 중요하다. 단일 고출력 $\mathrm{LED}$ 를 사용하기 보 다는 여러 개의 저출력 $\mathrm{LED}$ 를 사용하여 열밀도를 감소시켜 목표온도 이하로 유지하는 것이 효율적 이다.
(2) 히트싱크와 히트파이프를 이용하여 방열할 경우 자연대류 상태에서는 방열이 충분하지 않아 일정 시간 경과 후 $\mathrm{LED}$ 의 $\mathrm{PCB}$ 온도가 $100{ }^{\circ} \mathrm{C}$ 이상으로 상승한다. 하지만 팬을 사용하여 강제대류로LED 를 냉각시키면 $\mathrm{PCB}$ 온도가 최저 약 $42{ }^{\circ} \mathrm{C}$ 로 감소 되어 만족할 만한 방열 효과를 기대할 수 있다.

(3) LED 방열을 위해서 사용한 히트싱크 및 히트파이 프 모두 강제대류인 경우 방열성능을 만족하나, 히 트 파이프가 상대적으로 고가이므로 경제성을 고 려할 때는 히트싱크가 우수하다고 판명되어진다. 하지만 히트싱크의 부피가 상대적으로 커야하고 이에 따른 공간상의 문제가 대두되므로 이를 극복 하기 위해서는 히트파이프를 사용하는 것이 필요 하다.

(4) 팬 기동시 기동전력이나 베어링 마모를 고려하지 않는다면 팬의 기동 및 정지 알고리즘을 통해 팬 의 수명 및 팬의 전력소비를 약 2.7 배 정도 향상 시킬 수 있을 것으로 기대된다.

\section{References}

[1] S.J.Kim,"High energy efficient appliances on small and lightweight thermal technology", Knoweledge economy research planning project final report, pp.12, March 2009

[2] Lan Kim, Jong Hwa Choi and Moo Whan Shin, "Thermal analysis of LED array system with heat pipe," Thermochimica Acta, Vol 455, Issues 1-2 ,pp. 21-25, 1 April 2007.

[3] S. Liu, J. Yang, Z Gan and X. Luo, "Structural Optimization of a Microjet Based Cooling System for High Power LEDs", International Journal of Thermal Sciences, Vol. 47, pp. 1086-1095, 2008.

[4] Huanting Chen, Yijun Lu, Yulin Gao, Haibing Zhang, Zhong Chen, "The performance of compact thermal models for LED package", Thermochimica Acta, Vol.488, Issues 1-2, pp. 33-38, 5 May 2009.

[5] B. D .Kang, H. W. Kang, H.W.Kang, "The Effects of the Second heat source on heat sink of LED Head Lamp", KASE, 2007

[6] Chun-Jen Weng, "Advanced thermal enhancement and management of LED packages", International Communications in Heat and Mass Transfer, Vol.36, Issue 3, pp. 245-248, March 2009.

[7] S. H. Hwang, S. J. Park, Y. L. Lee "A Study of Optimal 
Thermal Design for a 10W LED Lamp", Journal of KAIS, Vol. 7, pp. 2317-2322 July 2010

[8] S. H. Hwang, Y. L. Lee, "Study on Thermal Performance of Multiple LED Packges with Heat Pipes" Journal of KSME, Vol. 35, pp. 569-575, 2011

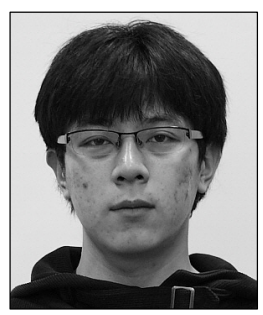

- 2010년 2월 : 공주대학교 기계설 계공학전공 (공학학사)

- 2010년 3월 현재 : 공주대학 교 대학원 석사과정

<관심분야>

열유체공학, 에너지공학

이 영 림(Young Lim Lee)

[정회원]

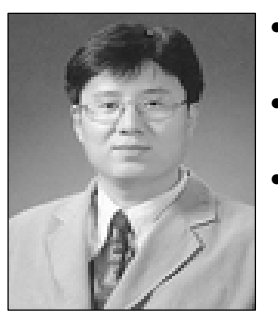

- 1995년 5월 : U of Texas at Austin 기계공학과 (공학박사)

- 1996년 8월 2000년 2월 : 삼 성자동차삼성전자 책임연구원

- 2000년 3월 현재 : 공주대학 교 기계자동차공학부 교수

<관심분야>

열유체공학, 에너지공학, 자동차공학 